\title{
A Study of the Normal Morphological Variations of Adult Nigerian Human Cadaveric Liver
}

\author{
Emue E. B ${ }^{1}$, D. S. Amaza ${ }^{2}$, Nuhu Sambo ${ }^{3}$, Luteino L. Hamman ${ }^{2}$, Nggada H.A ${ }^{3}$ \\ M. Tarfa ${ }^{2}$. \\ ${ }^{I}$ Department of Anatomical Sciences, Faculty of Basic Medical Sciences, University of Abuja, Nigeria. \\ ${ }^{2 \& 3}$ Departments of Human Anatomy and Human Physiology respectively, College of Medical Sciences, \\ University of Maiduguri, P. M. B. 1069, Maiduguri, Borno State, Nigeria. \\ ${ }^{3}$ Department of Histopathology, College of Medical Sciences, University of Maiduguri, Borno State, Nigeria.
}

\begin{abstract}
Many a times, both anatomist and morbid anatomist have been called upon to use physical features of organs of human body to determine the sex of an individual. This study was conducted to determine the variations in the morphology of an adult human cadaveric liver in Nigeria. Collections of adult human livers 62 (38 male and 24 female) of > 25 years of age was carried out for a period 3 years between March, 2008 and February, 2010 at the gross anatomy laboratories of University of Maiduguri and Abuja. The data were analyzed using percentage and two ways Analysis Of Variance (ANOVA) methods. The studied samples were all found to be darkish-brown, wedged shaped, and firm and friable. The commonest mean weight for male was $1516 \pm 0.1 \mathrm{~g}$ greater than that of female $1333 \pm 0.1 \mathrm{~g}$. The male mean length was $26.4 \pm 0.1 \mathrm{~cm}$; width, $15.7 \pm 0.2 \mathrm{~cm}$; and thickness, $6.0 \pm 0.2 \mathrm{~cm}$ being greater than that of female length, $25.4 \pm 0.2 \mathrm{~cm}$; width, $15.0 \pm 0.1 \mathrm{~cm}$ and thickness, $5.5 \pm 0.2 \mathrm{~cm}$ respectively. There was no sex significant variations, $P>0.05$ in all the studied parameters. This study may be useful in sex determination, studying, research and surgical purposes; and also as diagnostic stools during forensic investigations. However, physiological, pathological, genetic and environmental factors may be responsible for the differences in the weight in both sexes and populations, and require further evaluation.
\end{abstract}

Key word: Normal Morphology, Human Cadaveric Liver, Nigeria.

\section{Introduction}

The liver is the largest gland in the body situated in the right upper quadrant of the abdominal cavity [2, 3,4 , and 7]. It secretes bile and performs a number of other functions which are metabolic (chiefly), synthetic, storage, excretory and protective in a variety of ways [2]. The liver supports almost every organ in the body and is vital for survival. Because of its strategic location and multidimensional functions, the liver is also prone to many diseases [7]. After death, visceral change begins at the molecular level and sequentially progresses to microscopic and gross morphology [9]. In human liver familiar with the location and structure, led to better understanding of liver disease and chronic liver disease self-rehabilitation to strengthen Medical education [10]. This study was conducted to determine the normal variations in the morphology of an adult human cadaveric liver in Nigeria.

\section{Methodology}

62 adult human livers ( 38 male and 24 female) of ages $>25$ years were studied over a period 3 years between March, 2008 and February, 2010 at the gross anatomy laboratories of University of Maiduguri and University of Abuja, Nigeria. The livers were carefully dissected out from the Cadavers in the two laboratories. An only cadaver whose clinical history excludes liver pathology was used for this study. They were immediately assessed macroscopically and morphometrically using the following parameters: color and shape by physical observation, consistence by feeling; measurements of weight with beam balance weighing scale, length and width with the aid of graduated measuring meter rule, and thickness with venier caliper. The organs were placed in anatomical position before examinations were carried out. All data obtained from the measurements were analyzed by percentage method and Analysis Of Variance (ANOVA) using Instat 3 Graph Pad Guide, 1998. 


\section{Result}

Table 1: Descriptive analysis of the Percentage color, shape and consistency of adult cadaveric liver

\begin{tabular}{|l|l|l|l|}
\hline Sex & Color = Darkish-brown (No. /\%) & Shape = wedge (No. /\%) & $\begin{array}{l}\text { Consistency = firm and } \\
\text { friable (No. /\%) }\end{array}$ \\
\hline Male & $38(100)$ & $38(100)$ & $38(100)$ \\
\hline Female & $24(100)$ & $24(100)$ & $24(100)$ \\
\hline
\end{tabular}

No $=$ number. $\%=$ percentage.

The results from Table 1 show that all the colour, shape and consistency of the gland were all (100\%) darkish-brown, wedge-shape, and firm and friable respectively.

Table 2: Descriptive analysis of Weights Percentage, Mean and $\mathrm{P}$ values of adult cadaveric liver

\begin{tabular}{|c|c|c|c|c|c|c|c|}
\hline \multirow[b]{2}{*}{ Sex } & \multicolumn{2}{|c|}{$1200-1400 \mathrm{~g}$} & \multicolumn{2}{|c|}{$1500-1700 \mathrm{~g}$} & \multicolumn{2}{|c|}{$1800-2000 \mathrm{~g}$} & \multirow[b]{2}{*}{ P.value } \\
\hline & (No./\%) & Mean \pm SD & (No./\%) & Mean \pm SD & (No./\%) & Mean \pm SD & \\
\hline Male & $4(11)$ & $1293 \pm 0.2$ & $31(81)$ & $1516 \pm 0.1$ & $3(8)$ & $1812 \pm 0.1$ & \\
\hline Female & $20(83)$ & $1333 \pm 0.1$ & $3(13)$ & $1501 \pm 0.3$ & $1(4)$ & $1801 \pm 0.1$ & $P>0.05$ \\
\hline
\end{tabular}

$\mathrm{g}=$ gram. No $=$ number. $\%=$ percentage. $\mathrm{STD}=$ Standard Deviation. $\mathrm{P}=$ Probability value.

Table 2 shows that most (81\%) of the male weighs between $1500-1700 \mathrm{~g}$ with a mean of $1516 \pm 0.1 \mathrm{~g}$. Most $(83 \%)$ of the female weighs $1200-1400 \mathrm{~g}$ with a mean of $1333 \pm 0.1 \mathrm{~g}$. The least for male weighs $1200-1400 \mathrm{~g}$ $(11 \%)$ with a mean of $1293 \pm 0.2 \mathrm{~g}$, and $1800-2000 \mathrm{~g}(8 \%)$ with a mean $1812 \pm 0.1 \mathrm{~g}$. The least for female had $1500-1700 \mathrm{~g}(13 \%)$ with a mean $1501 \pm 0.3 \mathrm{~g}$, and $1800-2000 \mathrm{~g}(4 \%)$ with a mean $1801 \pm 0.1 \mathrm{~g}$. There was no significant differences between male and female with $\mathrm{P}>0.05$.

Table 3: Descriptive analysis of the mean length, width and breadth of adult cadaveric liver

\begin{tabular}{|l|l|l|l|l|}
\hline \multirow{2}{*}{ Sex } & Length $(\mathrm{cm})$ & Width $(\mathrm{cm})$ & Thickness $(\mathrm{cm})$ & \\
\cline { 2 - 4 } & Mean \pm SD & Mean \pm SD & Mean \pm SD & P.value \\
\hline Male & $26.4 \pm 0.1$ & $15.7 \pm 0.2$ & $6.0 \pm 0.2$ & \multirow{2}{*}{ P $>0.05$} \\
\hline Female & $25.4 \pm 0.2$ & $15.0 \pm 0.1$ & $5.5 \pm 0.2$ & \\
\hline
\end{tabular}

$\mathrm{cm}=$ centimeter $. \mathrm{SD}=$ Standard Deviation. P.value $=$ probability value

Table 3 reveals that the male human liver has the highest mean values respectively for the length $26.4 \pm 0.1 \mathrm{~cm}$; width $15.7 \pm 0.2 \mathrm{~cm}$, and thickness $6.0 \pm 0.2 \mathrm{~cm}$. The female liver has the lowest mean and median values respectively for the length $25.4 \pm 0.2 \mathrm{~cm}$; width $15.0 \pm 0.1 \mathrm{~cm}$, and thickness $5.5 \pm 0.2 \mathrm{~cm}$. There was no significant sexual differences with $\mathrm{P}>0.05$.

\section{Discussion}

This study has shown that the colour of the cadaveric liver was darkish brown and was contrary to the colour of liver from living subjects which was reported to be bright reddish in appearance [5, 7, 8, and 10]. The darkish brown color in this study may be due changes at the molecular level which sequentially progresses to microscopic and gross morphology [9]. Again, the effect of the fixatives and environmental factors may also influence the color. This study has shown that all the liver was wedged-shaped (four-sided pyramid that lies on one side with the apex pointing to the left) [2]. However, other studies showed that its shape was somewhat cuneiform and triangular [3,7]. Furthermore, this study revealed that the consistency was firm and friable but other literature reported it to be soft and friable [2, 7, and 10]. Our study has shown that the incidence of most $(81 \%)$ male weighs between $1500-1700 \mathrm{~g}$ with a mean of $1516 \pm 0.1 \mathrm{~g}$ was higher than most $(83 \%)$ of the female that weighs between $1200-1400 \mathrm{~g}$ with a mean of $1333 \pm 0.1 \mathrm{~g}$. [2, 10] However, this result is similar to the Indian adult populations, in which male weighs about $1400-1800 \mathrm{~g}$ and $1200-1400 \mathrm{~g}$ in female with a range of 1000 2500g [2] ; but higher than China's adult liver weight, 1157-1447g for men and women $1029-1379 \mathrm{~g}$ [10]. The increased weight recorded higher in the male than the female may be attributed to increased haematopoietic activities to meet up efficiently the increased muscle mass functions of the former producing red cell volume greater than the latter [5,6]. The adult liver length, width and thickness of $25.8 \mathrm{~cm}, 15.2 \mathrm{~cm}$ and $5.8 \mathrm{~cm}$ reported among the China population[10] were respectively in this study lower than the male mean values for length was $26.4 \pm 0.1 \mathrm{~cm}$; width $15.7 \pm 0.2 \mathrm{~cm}$ and thickness $6.0 \pm 0.2 \mathrm{~cm}$, but higher than the female length $25.4 \pm 0.2 \mathrm{~cm}$; width $15.0 \pm 0.1 \mathrm{~cm}$, and thickness $5.5 \pm 0.2 \mathrm{~cm}$. In this study, there was no sex significant differences $(\mathrm{P}>0.05)$ in all the parameters. 


\section{Conclusion}

This study has demonstrated that most adult cadaveric liver of Nigerians was darkish-brown, wedge shaped, and firm and friable. The commonest mean weight for male was $1516 \pm 0.1 \mathrm{~g}$ and that of female $1333 \pm 0.1 \mathrm{~g}$. On all the parameters studied, there was no sex significant variations, $\mathrm{P}>0.05$. This study may be useful in determination of the sex, studying, research and surgical purposes; and also as diagnostic stools during forensic investigations. However, physiological, pathological, genetic and environmental factors may be responsible for the differences in the weight in both sexes and populations, and require further evaluation.

\section{Acknowledgement}

The authors express deep regards to all those that ensures success of this study.

\section{References}

[1] Bal M.S; Singh S.P; Boda, V.K. 1; Oberoi, S.S and Kanwal, S. Pathological Findings in Liver Autopsy. JIAFM, 2004; 26(2). ISSN 0971-0973

[2] Chaurasia, B D. Human Anatomy. Regional and Applied, Lower Limb and Abdomen. $1^{\text {st }}$ ed. 1989. Shalhra, Delhi. pp 221-225.

[3] John, V.B. Anatomy. ${ }^{\text {st }}$ ed. Waverly press. United State of America 1976. pp368-369.

[4] Keith, L.M., and Arthur F.D. Clinically Oriented Anatomy. $5^{\text {th }}$ ed. 2006. USA. pp 289-300.

[5] Keith, L .M. The developing Human Clinically Oriented Embryology. Canada. 1973. Pp177.

[6] Sadler, T.W. Lang man's Medical Embryology. $9^{\text {th }}$ ed. 2003. pp 300.

[7] Wikipedia, free encyclopedia. [Online]. Cited 2010. Available from: http://en.wikipedia.org/wki/Liver

[8] Digestive Disorders Health Center. [Online] cited 2009. Available from: http://www.webmd.com/digestive.disorders/picture-of-thestomach.

[9] Presnell, S E. and Stephen, J C. Postmortem changes and body. [Online] Update: Sep 22, 2009. Available from: http://emedicine.medscape.com/article/1680032.

[10] In Human Liver Location and morphology. [Online] cited 2010. Available from: http://www.ganbling.com.cn/YLX.HTM 